\title{
A Teaching Attitude Adjusting Model for College Teachers Based on
}

\section{Attitude Theories}

\author{
Linying Zhang \\ School of Economics and Management, Nanjing University of Science and Technology \\ Nanjing 210094, China \\ E-mail: z.ly@163.com \\ Zhijun Han \\ School of Economics and Management, Nanjing University of Science and Technology \\ Nanjing 210094, China
}

\begin{abstract}
Teaching attitude of teachers influences the accomplishment of teaching objectives, the quality of teaching and students' learning outcomes and is the main variable in the process of higher education teaching. By referring to attitude theories and group characteristics of college teachers, this paper analyzes the elements that influence teaching attitude of teachers, establishes a teaching attitude adjusting model for college teachers, aiming at providing new administrative framework and critical control point for the management of teaching attitude of college teachers.
\end{abstract}

Keywords: Higher education, Teaching attitude, Teaching quality

Teaching attitude influences the exterior appearance of teachers' knowledge to a great extent and restricts the development of teaching capacity. Besides specialty knowledge and teaching techniques, teaching attitude is also a key determinant element in teaching performance of higher schools. Yao Liming (2003), Chinese scholar, did research on effective teaching characters and believed, "Teaching has always been carried out by teachers and students under certain mood background. The mood status of teachers and students determines the outcome and efficiency of the teaching." Of course, teaching activities are restricted and influenced by objective elements, such as teaching outlines, teaching materials and students; however, teaching attitude determines the implementation effects of teaching activities. The setting down of teaching plans, the choosing of teaching materials, the selecting of teaching strategies and the designing of mutual activities in teaching are all done or directed by teachers. The teaching effects brought by a positive teaching attitude will certainly and remarkably be different from that by a negative teaching attitude. Kerry D (2001) pointed out that if an effective teacher had demonstrated enthusiasm in discipline contents and in specialty practices of teaching, he or she would be able to activate students' enthusiasm by various means. In addition, attitude of teachers also exerts influences on the formation of students' personalities. Personality-oriented education and humanistic learning theory hold that teaching not only includes knowledge imparting and the cultivation of cognitive capacities but also includes developing sensibility volition, and is an overall personality education. Positive and enthusiastic teaching and living attitude of teachers in teaching activities will exert subtle influence on the formation and the development of students' various psychological characters. Teaching practices have proved that students' psychological characters usually will develop following the track of teaching attitude of teachers.

Researches on teaching quality home and abroad have always been focusing on knowledge levels and personality characters of teachers and few researchers are about teaching attitude of teachers. This paper first analyzes group characters of college teachers and elements that influence teaching attitude of college teachers, then puts forward teaching attitude adjusting model for college teachers, and explores the application of attitude theories in the teaching of higher schools, aiming at providing theoretical supports and administrative framework for the management of teaching attitude of college teachers.

\section{A review of theories related to attitude}

The definition of attitude given by social psychology is that attitude, consisting of cognition, sensibility and will, is a comparatively stable reaction trend towards certain special object. Attitude itself is not an action, but attitude restricts action. Attitude exerts direction and drive towards a person's reaction.

The formation and the change of attitude is not an instant action, but is a gradual and socialized process. Kelmen, social 
psychologist, opines that the formation of an attitude will undergo three processes, obedience, recognition and internalization. An individual receives new information about attitude object, reevaluates the values of the attitude object, and fixes new action trend s, after which a new action attitude is formed. With regards to the methods to change attitude, in the persuasion and attitude change model (refer to Figure 1) put forward by Hovland C.I together with other psychologists, it is stated that there are at least four elements that influence the change of attitude, namely, persuader, information, situation and personal character of an individual. In the process of attitude change, an individual first studies the contents of the information and then on the basis of the study, the sensibility is transferred, in which process the sensibility on one object is transferred to other objects related to the original object. When the information received is discrepant with the original attitude, the individual will be psychologically nervous, at which stage consistency system will start to take effect. However, the effect of persuasion mainly depends on the amount and the quality of the refution caused by the discrepancy of information. If the process of the refution is interrupted, either the attitude is changed or the information source is debased and the persuasive information is deliberately distorted to refuse the information.

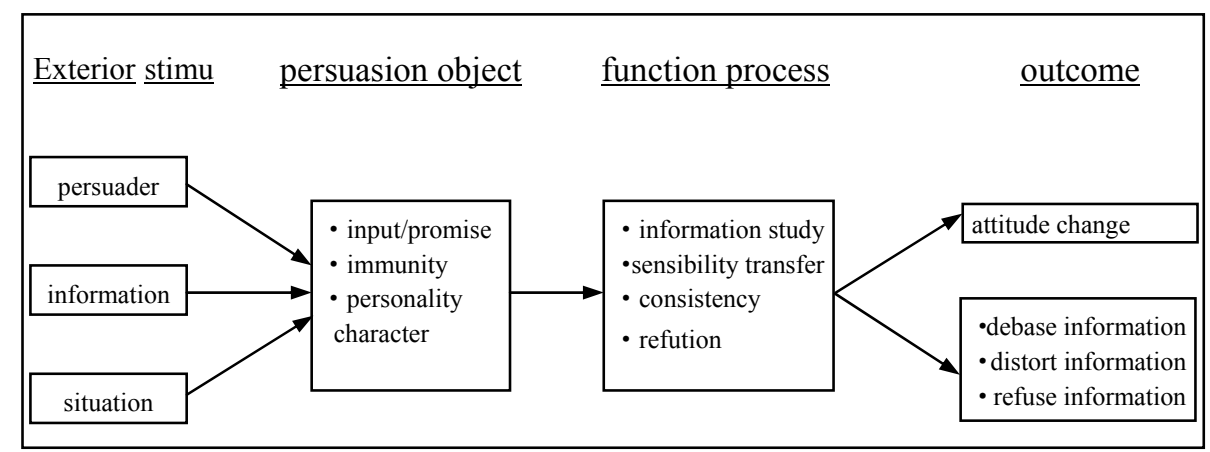

Figure 1. Persuasion and Attitude Change Model

Psychologists had put forward many theories to explain why attitude changes. Cognitive dissonance theory believes that if elements of the cognitive system of an individual are dissonant, the inner feeling of the individual will be unhappy and nervous, resulting in the change of attitude. Participation bringing about change theory advocates that attitude of human beings is changed by way of group standards and values. Human beings are living in groups, so the properties and standards of group activities determine the attitude of human beings. Reference group changing attitude theory is of the opinion that the recognition of each individual towards his or her status and role in a group is an important basis for the individual to form individual attitude and his or her attitude will change with the influence of the reference group.

To understand and study attitude theories and their relevant research outcomes will be of great significance for college teachers in how to keep positive and active teaching attitude and to change negative and listless attitude in the process of teaching in higher schools.

\section{Analysis on elements that influence teaching attitude of college teachers}

Teaching attitude, influencing teaching quality of higher schools, is incarnated by the negativeness and accidie of teachers towards teaching tasks. The negativeness and accidie of teachers is a reaction result of the accumulation of low intensities from their moods when confronted with pressures. Many reasons will lead to the negativeness and accidie of teachers, of which exterior elements include work pressure, intensive colleague relationship, bad performance of students, hardship in promotion and few chances to participate in decision-making and interior elements include personality character, value concept, and the level of self-performance. To combine with the specific situations of Chinese college teachers, there are mainly the following aspects:

\subsection{The influence of talent collective effect and social comparison mode on teaching attitude of teachers}

Personal social comparison modes of teachers also influence the change of teaching attitude. Wood J.V (1989) classified social comparison mode into four types: up recognition, low recognition, up comparison and low comparison. Teachers adopting up recognition focus on the resemblance of themselves with more excellent persons (poles) by which they can recognize their values and deficiencies, which is conducive to the formation of positive teaching attitude. Teachers adopting up comparison will take persons who are better than them in certain aspects as their opponents and negatively evaluate themselves, which can only deepen their feelings of envy and frustration. Teachers adopting low recognition tend to think that they and their futures are similar to those who have gone through frustration or who perform worse, resulting in their negative teaching attitude. Teachers adopting low comparison tend to think that the capacities of other people are rather bad and others are easy to be frustrated. This kind of thinking can also easily trigger positive feeling, but this is a negative way to trigger positive attitude, so it should not be advocated. 
Generally, teachers are specialized in certain field and have profound theoretical knowledge, so college teacher group is a typical talent collective group. The negative effect of conflicts among talents will exert negative influence on personal cognition, mood and other psychological elements of teachers. Teachers who adopt up comparison and low recognition will easily form negative and listless teaching attitude resulting in their lack of impetus in work and their low teaching quality.

\subsection{The influence of work pressure and handling manner on the attitude of teachers}

In modern times, the updating of knowledge is becoming quicker and quicker, which demands teachers to spare more efforts to study so as to keep pace with the updating of knowledge. Meanwhile, the workload of teachers increases with the prevalence of higher education; the assessment and examination by schools for teachers increasingly grows with the implementation of education reform. Consequently, most teachers feel that they are under giant work pressure. If handling manner as against the pressure is not proper, it is easy for those teachers to treat teaching with negative and callous attitude. Handling manner is usually defined as the cognitive and action effort with orientation to manipulate, decrease or abide the pressures arising out of the demands that cannot be met. The research of Gerva K. and Joekes K (2003) indicates that to adopt direct handling manner aiming at problem resolving is good for teachers to secure positive and active teaching attitude and to adopt indirect handling manner with handling sensitivity problem as main task can easily lead teachers to form negative and listless teaching attitude.

\subsection{The influence of system guidance on the attitude of teachers}

The performance assessment and examination system of higher schools is the vane of the work of teachers. The influences of the assessment and examination system on teaching attitude of teachers are mainly shown in the following two aspects. Firstly, it is the influence of teaching evaluation. Variables in the process of teaching are complex. No unified "technical method" or "service procedure" can be followed. Usually, there exist discrepancies among students' evaluation, experts' evaluation and self evaluation of teachers. Improper handling will easily cause disputes and will become important inducement of negative teaching attitude of teachers. Secondly, the assessment and examination and encouragement towards college teachers mainly focus on the accomplishment of scientific research tasks, such as the scientific research projects taken on, the accomplishment awards gained, the academic theses papers published, the works (teaching materials) published and the patents obtained. The direction of the assessment and examination system pulls teachers to spend most of their energy on scientific researchers and to negatively treat teaching jobs.

\subsection{The Influence of organizational support on the attitude of teachers}

Organizational support refers to spiritual and material support for members of an organization, inclusive of to care for members, to listen attentively to members' complaints, to render help when members face problems, and to justly treat members. The care of schools to teachers will be good for teachers to ease their work pressures. The research of Haque and Nargis shows that intensive helps and supports of organizations towards teachers are effective to help them to ease work pressures and occupation accidie.

\section{Teaching attitude adjusting model for college teachers}

Teachers enjoy sublime social status. However, under the influences of the gap of realistic incomes, long term repetitive teaching, and many other elements bad for the formation of positive attitude, it is very easy for college teachers to feel frustrated and to debase their personal values, resulting in negative and listless teaching attitude. Therefore, the management of teaching attitude of teachers becomes a key in the improvement of current teaching performance. In addition, to change others' attitude is a management job and especially, is an important component of the work of leaders.

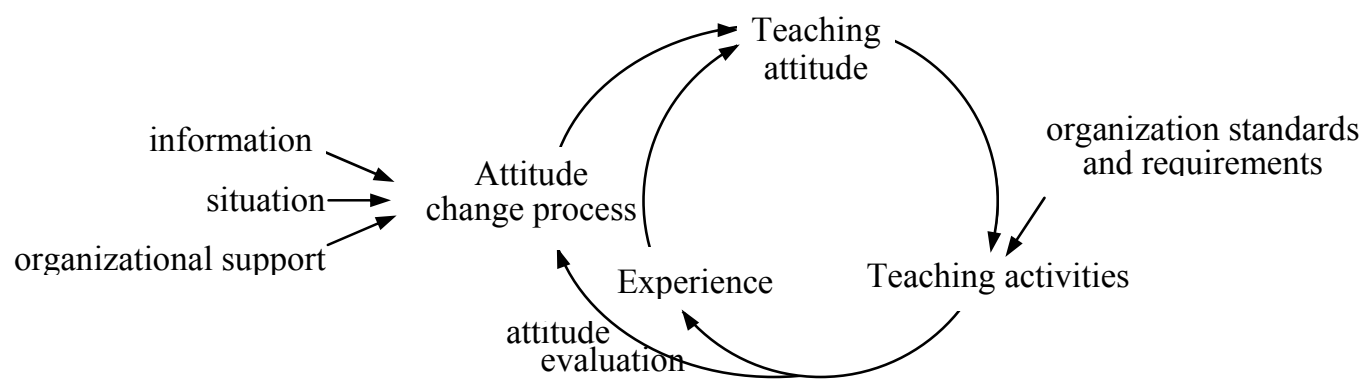

Figure 2. Teaching Attitude Adjusting Model for College Teachers

Modern management theory believes that management objects can be improved if the quality characters of the objects can be measured evaluated and be classified as good and bad. One typical improvement method is "PDCA" circulation proposed by Dai Ming. Attitude theories have proved that the attitude of human being determines his or her actions and 
the exterior action is the token of attitude. Therefore, if can be measured and evaluated, teaching attitude of teachers can also be improved. The teaching attitude model of teachers shown in Figure 1, an inner circulation attitude $\rightarrow$ activities $\rightarrow$ experience $\rightarrow$ attitude, shows the function of reciprocity mode of attitude action in teaching. Under the circumstance without outside interruption, human beings will trap in an intensified circulation, which is "actions determined by attitude", "the obtainment of experience" and "the consolidation of attitude by experience". There are two probable situations in the consolidation of attitude, one is positive consolidation, which refers to the consolidation of positive and active teaching attitude on the basis of active experience; the other is negative consolidation, which means that negative and listless teaching attitude becomes more negative after being beaten by experiences. The ideal state of teaching attitude management of teachers by higher schools is to consolidate positive teaching attitude and to correct negative teaching attitude.

The starting point of the attitude change circulation shown in Figure 2 is teaching evaluation. After being recognized, positive and active attitude is solidified by attitude consolidation. The objects (teachers) with negative and listless attitude to be changed enter into the process of attitude reflection and change. The key influencing elements in the process of teachers' attitude change include information, situation, organizational support and personality character. First of all, the information includes the attitude object information and the pole information of positive and active attitude. Attitude object information stimulates main bodies to change their cognition towards attitude objects, resulting in the unbalance among cognition, sensitivity and will. A re-balance of cognition, sensitivity and will pushes the change of the attitude of main bodies. Secondly, the pole information of colleagues provides reference for the change of attitude and is also a part of situation element. The ways and manners of information spreading influence the change of the attitude of main bodies. For teachers with different opinions, it is more effective to make an overall explanation than to just highlight strong points or weak points. In the process of information spreading, explicit conclusion is more effective than just to provide relevant materials and to let receivers make conclusions. Same information gained from various aspects are better that the information repetitively indicated by a single person. Thirdly, organizational support is the spiritual and material support for members of the organization, including to care for members, to listen attentively to members' complaints, to render help when members face problems, and to justly treat members. The care of organizations for teachers will help teachers to ease their work pressures and to eliminate risky elements which will lead to the occurrence of negative and listless attitude. The research of Haque and Nargis shows that intensive helps and supports of organizations towards teachers are effective to help teachers to ease their work pressures and negativeness and accidie. Administrators of schools, as the persuaders in changing the attitude of teachers, should provide stimulus cognition information to change the main bodies and direct the main bodies' understanding of situation elements. Practices have proved that the higher the prestige of administrators is, the more probably they influence the change of the attitude of main bodies. Fourthly, the personality character of an individual exerts significant influence on the formation and change of attitude. The formation of personality character is the outcome of long term environmental and physical influence, so personality character is hard to change. Nevertheless, under the organizational support and the help of colleagues, it is possible to change attitude by changing some specific characters of personality, such as hobbies and capacities. Besides, to standardize teaching actions and to clarify teaching requirement are also necessary methods to change the attitude of teachers. The researches of attitude theories have proved that to change the exterior actions of an individual can change his or her attitude because when an individual's exterior actions do not comply with his or her interior attitude, he or she will feel unhappy and will think out methods to make the two comply with each other. When one action is a publicly recognized as correct and he or she cannot participate in such an action, he or she will gradually change the inner dissonant attitude.

\section{Conclusion}

Because the elements that influence the change of attitude are in large number and are hard to determine and measure, the management of teaching attitude of teachers has always been a weak point in the management of teaching in higher schools. This paper, in accordance with attitude theories and other relevant theories, does a research on the mutual relationship among teaching attitude, teaching activities and the change process of teaching attitude, and points out the key controlling element in the management of teaching attitude of teachers in higher schools. Therefore, the management of teaching attitude of teachers in higher schools shall proceed from the following aspects. Firstly, a system for the management of teachers' attitude shall be established to evaluate the change of teaching attitude of teachers. Teaching attitude index shall be added into teaching evaluation. With regards to positive and active teaching attitude, schools shall apply encourage methods and ardently render supports; with regards to negative and listless teaching attitude, schools shall render care and directions to help them to change attitude. Secondly, the information channels for teaching shall be extended and the outer information stimuli shall be enlarged in order to change the attitude structures of teachers and to advance the change of negative and listless teaching attitude. Thirdly, teaching management shall be standardized, teaching requirements shall be clarified and teaching actions of teachers shall be regulated in order to accelerate the formation of positive and active teaching attitude by those imperative requirements. Fourthly, supportive and harmonious atmosphere shall be created to help teachers to change certain negative personality 
characters in order to change their attitude.

\section{References}

Gerva K \&Joekes K. (2003). U K teachers under stress: can we predict wellness on the basis of characteristics of the teaching job? Psychology and Health, (18), pp.457-471.

Haque M A \& Nargi A. (2003). Relationship between job stress and burnout:organizational support and creativity as predictor variables. Pakistan Journal of Psychological Research, (18) pp.139-149.

Hovland,C.I., Janis,L.L.\&Kelley,H.H. (1953). Communication and Persuasion. Yalo University Press.

Kerby D. (2002). Project team for teaching and evaluation (final report). Available at http://vpaa.truman.edu/PTFinalReport.pdf.

Meng, Qingmao \& Liu Hongyun. (2003). A research on the evaluation dimension structure and influencing elements in teaching effects of college teachers. Psychological Science, 4(23).

Wood J V. (1989). Theory and research concerning social comparisons of personal attributes. Psychological Bulletin, (22), pp. 520 - 537

Yao, Limin. (2001). The characteristics of effective teaching in colleges. Modern College Education. 